\title{
How Do Gain and Loss Incentives Affect Memory for Intentions Across Adulthood?
}

\author{
Horn, Sebastian S ; Freund, Alexandra M
}

\begin{abstract}
Objectives: Changes in motivational orientation across adulthood affect cognitive processes. The purpose of this research was to investigate if and how motivational incentives (gains or losses) affect prospective memory for intended actions in younger, middle-aged, and older adults. Method: The consequences of memory hits and misses and the framing of the memory tasks were experimentally manipulated between participants: In a gain-framing condition, participants accumulated rewards, dependent on the proportion of target events to which they responded accurately. In a loss-framing condition, participants received an initial endowment from which losses were deducted, dependent on the proportion of targets they missed. We measured memory accuracy, perceived task importance, and ongoing-task performance. Results: Gains and losses had different effects on memory across age groups: Age $\times$ Motivational Valence interactions emerged across 2 studies. Older adults showed relatively better memory performance to avoid losses than to achieve gains. Moreover, higher age was associated with lower memory performance (Study 1) and slower but more accurate decisions in an ongoing activity (Study 2). Discussion: The findings reveal that motivational incentives and the framing of consequences as gains or losses moderate the relation between age and memory performance. Older adults' memory performance may benefit when messages encourage the avoidance of losses. This may also help to design age-tailored interventions in applied settings (e.g., health-related behavior).
\end{abstract}

DOI: https://doi.org/10.1093/geronb/gbaa140

Posted at the Zurich Open Repository and Archive, University of Zurich

ZORA URL: https://doi.org/10.5167/uzh-190772

Journal Article

Accepted Version

Originally published at:

Horn, Sebastian S; Freund, Alexandra M (2021). How Do Gain and Loss Incentives Affect Memory for Intentions Across Adulthood? Journals of Gerontology, Series B: Psychological Sciences and Social Sciences, 76(4):711-721.

DOI: https://doi.org/10.1093/geronb/gbaa140 
RUNNING HEAD: AGING, MEMORY, GAINS AND LOSSES

How Do Gain and Loss Incentives Affect Memory for Intentions Across Adulthood?

Sebastian S. Horn, $\mathrm{PhD},{ }^{1}$ and Alexandra M. Freund, $\mathrm{PhD}^{1,2}$

${ }^{1}$ University of Zurich

${ }^{2}$ University Research Priority Program "Dynamics of Healthy Aging”

Reference: Horn, S., \& Freund, A. M. (in press). How Do Gain and Loss Incentives Affect Memory for Intentions Across Adulthood? The Journals of Gerontology: Psychological Sciences.

Note: This preprint is not the final copy of the record and may not exactly replicate the final version of the article.

\section{Author Note}

Dr. Sebastian S. Horn. Department of Psychology, University of Zürich, Switzerland.

Prof. Dr. Alexandra M. Freund, Department of Psychology, University of Zürich,

Switzerland and Research Priority Program Dynamics of Healthy Aging.

Funding. This work was supported by Swiss National Science Foundation (SNF) grant 100019-185463 to Sebastian Horn.

Acknowledgements. We thank the members of the Life-Management Team at the University of Zurich for helpful comments. Parts of this research were presented at the annual meeting of the Psychonomic Society, Montreal, Canada, November 2019, and at the International Conference on Aging and Cognition, Zurich, Switzerland, April 2019.

Further information. Supplemental materials are available at the Open Science Framework at https://tinyurl.com/gainlossmemory (including supporting information, data, and stimulus materials). This research was not pre-registered. Analysis scripts are available from the first author upon request.

Word count. This manuscript has 4869 words (abstract, text), 50 references, 3 Tables, and 2 Appendices.

Correspondence. Correspondence concerning this article should be addressed to Sebastian S. Horn, University of Zürich, Department of Psychology, Binzmühlestr. 14 (Box 11), 8050 Zürich, Switzerland. Email: horn@psychologie.uzh.ch 


\begin{abstract}
Objectives: Changes in motivational orientation across adulthood affect cognitive processes. The purpose of this research was to investigate if and how motivational incentives (gains or losses) affect prospective memory for intended actions in younger, middle-aged, and older adults.
\end{abstract}

Method: The consequences of memory hits and misses and the framing of the memory tasks were experimentally manipulated between participants: In a gain-framing condition, participants accumulated rewards, dependent on the proportion of target events to which they responded accurately. In a loss-framing condition, participants received an initial endowment from which losses were deducted, dependent on the proportion of targets they missed. We measured memory accuracy, perceived task importance, and ongoing-task performance.

Results: Gains and losses had different effects on memory across age groups:

Age $\times$ Motivational Valence interactions emerged across 2 studies. Older adults showed relatively better memory performance to avoid losses than to achieve gains. Moreover, higher age was associated with lower memory performance (Study 1) and slower but more accurate decisions in an ongoing activity (Study 2).

Discussion: The findings reveal that motivational incentives and the framing of consequences as gains or losses moderate the relation between age and memory performance. Older adults' memory performance may benefit when messages encourage the avoidance of losses. This may also help to design age-tailored interventions in applied settings (e.g., health-related behavior).

Keywords: Gains and losses, cognitive aging, motivation, prospective memory, cognitive modeling 


\section{How Do Gain and Loss Incentives Affect Memory for Intentions Across Adulthood?}

Lifespan developmental theory suggests that the frequency of gain- and loss-related experiences changes systematically across adulthood (Baltes et al., 1998): Younger adulthood provides many opportunities for growth and investment, whereas resource limitations become more prevalent in older adulthood. There is evidence that people's motivational orientation changes correspondingly, from a primary focus on achieving gains in younger adults towards the maintenance of resources and avoidance of losses in older adults (e.g., Freund \& Ebner, 2005; Heckhausen et al., 1989; Ogilvie et al., 2001; Staudinger et al., 1995). Such changes in motivational orientation across adulthood may influence cognitive processes, including how and what people remember (Castel et al., 2016; Hargis et al., 2019; Hess \& Emery, 2012).

Past research has demonstrated that memory performance is particularly affected when tasks involve a motivational component that is relevant for subsequent actions and when there is a realistic prospect of avoiding negative or achieving positive consequences (e.g., Bowen \& Spaniol, 2017; Depping \& Freund, 2013; Mather \& Carstensen, 2015). Hence, if people are oriented towards achieving gains or preventing losses, this may result in relatively better memory when information has to be remembered that matches with their motivational orientation. In the current research, we examined how gains and losses following memory success and failure, respectively, affect performance from this motivated-cognition perspective.

\section{Aging and Memory for Intentions}

To experimentally investigate the interplay between motivation and remembering, we focused on memory for intentions (prospective memory; PM). Goal orientation likely plays an important role in PM, because PM involves remembering intended actions in the future as part of explicit planning (Cohen \& Hicks, 2017; Kliegel et al., 2001; McDaniel \& Einstein, 2000; Rummel \& McDaniel, 2019; Smith et al., 2007). So far, research on aging and PM has 
largely focused on cognitive processes (e.g., Einstein \& McDaniel, 1990; Henry, et al., 2004; Horn et al., 2013; Logie \& Maylor, 2009; Scullin et al., 2012; Smith \& Bayen, 2006; Uttl, 2008). For instance, age differences in PM are usually smaller when salient cues support retrieval and reduce attentional demands to monitor the environment (Craik, 1986; Kliegel et al., 2008; Park et al., 1997). Moreover, in laboratory settings, younger adults show higher memory performance than older adults in event-based PM tasks (remembering to execute an action when a target event occurs) and time-based PM tasks (remembering to execute an action at a specific clock time).

\section{Motivational Perspective}

Although research on cognitive processes has significantly advanced our understanding of age-related differences in PM, evidence highlighting the importance of motivational and social aspects in PM tasks has begun to accumulate (e.g., Brandimonte et al., 2010; Gollwitzer \& Cohen, 2008; Schnitzspahn et al., 2011). Given the characteristic future- and action-orientation of PM, performance could be particularly sensitive to motivational influence in PM tasks. Hence, a motivational perspective on PM promises to provide an ecologically more valid and complete picture on how younger and older adults remember delayed intentions across different contexts (Phillips et al., 2008).

A first suggestion to link goal constructs and PM processes was made in Penningroth and Scott's (2007) motivational-cognitive model. Following prominent goal theories (Kruglanski et al., 2002), a key notion in this model is that remembering intentions involves concrete activities or means that support higher-level goals. From this perspective, relations between PM tasks and goals can be viewed as hierarchical networks, in which PM tasks are at a relatively concrete level (e.g., remember to take medication) associatively linked with further midlevel goals (e.g., keep adequate blood pressure) and more abstract goals at the high end (e.g., maintain good health). Consequently, PM tasks that are strongly associated 
with currently relevant higher-level goals may have a higher likelihood of being fulfilled than others. In line with this, both younger and older adults tend to report higher importance of PM tasks that are related to their personal goals. Moreover, self-reports suggest that younger and older adults' everyday PM demands are motivated by different goals and concerns (Penningroth \& Scott, 2019). Here, we assume that the extent to which younger and older adults differ in motivational orientation (i.e., the tendency to be moved by approaching gains or avoiding losses; Freund \& Ebner, 2005) influences their evaluation of incentives in a PM task. Dependent on the kinds of goals a person holds, the same consequences of a remembered or forgotten intention can have different relevance. For example, a primarily gain-oriented person might be strongly motivated to remember attending workout class to further increase physical fitness. In contrast, a person who is primarily loss-avoidance oriented might be more motivated no to forget exercising to prevent health issues. Hence, forgetting the same intention might be perceived as foregone gain or a loss, depending on a person's motivational orientation. Based on these considerations, we assumed (a) that motivational orientation could be an important source of age-related variability in PM and (b) that motivational incentives (gains or losses) resonating with a person's orientation regarding higher-level goals could have stronger impact on PM performance. We are not aware of experimental studies that have tested the effects of motivational incentives on PM in middleaged or older adults. A first aim of the current studies was to investigate the potentially agedifferential impact of gain and loss incentives on PM.

Only few studies on PM have manipulated motivation through incentives (tokens or monetary reward) or through social relevance (for overviews, see Cook et al., 2015; Walter \& Meier, 2014). In contrast, several studies have manipulated importance of PM tasks through verbal instructions and typically found that emphasizing the importance of PM increases memory accuracy (e.g., Ball \& Aschenbrenner, 2018; Kliegel et al., 2001; Walter \& Meier, 
2014). These different manipulations could elicit different forms of motivation that in turn may influence PM via different routes (e.g., more or less effortful monitoring to detect PM targets; for further discussion, see Study 2). Specifically, it has been suggested that externally provided incentives (gains or losses) and participants' intrinsic interest in a given PM task could have independent and potentially divergent effects on PM performance (see Peter \& Kliegel, 2018; Walter \& Meier, 2014). Because subjective relevance of a PM task may have incentive-independent effects on PM, we additionally measured participants' perceived importance of the PM tasks. The aim was to quantify the extent to which participants' intrinsic interest in performing the PM task may affect performance above and beyond the external incentive manipulation and to disentangle potentially different motivational sources affecting memory performance.

Taken together, we investigated how motivational incentives influence PM across adulthood by manipulating the consequences following memory failure and success in terms of gains and losses, respectively, that were added to or subtracted from a person's payoffs. Based on the notion that maintenance of resources and prevention of losses become particularly relevant in older adulthood (Freund \& Ebner 2005), we expected age-differential effects of gain- and loss-related consequences on memory performance (Age $\times$ Motivational Valence interactions in PM performance). To the extent that older adults are more motivated by incentives to avoid losses than to achieve gains, they might be more sensitive to losses and show relatively better PM with loss-related than gain-related consequences. This would suggest that age differences in PM are smaller in a loss context than in a gain context. Based on previous cognitive aging research, we also expected age differences in memory performance: older adults in event-based PM tasks often show lower memory performance than younger adults (e.g., Kliegel et al., 2008; Smith \& Bayen, 2006).

\section{Study 1}


In Study 1, we examined the aforementioned propositions with a motivational incentive/framing manipulation: in a gain condition, participants could accumulate reward, dependent on the proportion of target events that they responded to correctly. In a loss condition, participants received an initial endowment from which losses were deducted, dependent on the proportion of target events they missed. In addition, we measured participants' perceived importance of the PM task.

\section{Method}

Participants and design. The final sample of Study 1 included 146 adults (49\% female) in the age range 18 to 83 years, who participated online via their browser (further information about sample size planning of both studies and about online data collection is in Supplement 5 and 8, respectively). We aimed at an approximately equal proportion of younger (18-34 years; $n=48)$, middle-aged (35-60 years; $n=46)$, and older adults $(61-83$ years; $n=52)$. Table 1 shows participant characteristics. Participants were native/fluent German speakers and reported good health. Participants were randomly assigned to one of two experimental motivational-framing conditions: gains vs. losses. Participants' chronological age and their perceived PM-task importance were included as continuous variables in the analyses.

Materials and procedure. Participants read initial instructions for an event-based PM task that was embedded in an unrelated questionnaire. Following procedures by Logie and Maylor (2009), participants were instructed to remember to klick on a smiley-face symbol whenever it occurred at the bottom of a questionnaire page. Moreover, participants were informed that, depending on their PM performance, they could contribute up to $2.5 \mathrm{CHF}$ $(\sim 2.5 \mathrm{USD})$ for a donation. Older adults often express a preference to donate their financial reimbursement for participation in experimental studies (Freund \& Blanchard-Fields, 2014). To provide motivational incentives that are also appealing to older adults, we applied a previously tested procedure in which performance-contingent payoffs were donated to a 
humanitarian organization after the study (Doctors Without Borders). To emphasize the relevance of even small amounts gained or lost, participants were informed that approximately $1 \mathrm{CHF}$ may help to provide medical treatment for six children suffering from malaria or two portions of additional nutrition for malnourished children (source: www.doctorswithoutborders.org). In the gain-frame condition, participants were informed that they could accumulate up to $2.5 \mathrm{CHF}$ for this purpose, contingent on the proportion of PM targets they would respond to correctly. In the loss-frame condition, participants started with an amount of $2.5 \mathrm{CHF}$ and were informed that they could lose this initial endowment, contingent on the proportion of PM targets they would miss. Participants then worked selfpaced on a series of questionnaire pages (completion duration: $M d n=14 \mathrm{~min} ; S D=3 \mathrm{~min}$ ). Ten PM target events were uniformly interspersed among the questionnaire pages. PM performance was scored in terms of whether a smiley face was clicked before a participant moved to the next screen $(\mathrm{PM}$ miss $=0 ; \mathrm{PM}$ hit $=1)$. Participants also completed a test of cognitive speed and provided ratings of their perceived absolute importance of the PM task (Likert scale; 1 = unimportant; 7 = very important). Finally, we included checks to ensure the quality of the data. We debriefed and cued participants at the end of a session whether they could remember the PM action. Participants who, upon this explicit request, could not indicate the PM action and additionally never performed PM task during the study were excluded from further analyses ( $n=9$ out of 155 participants in Study 1$)$, as is common in PM studies (Smith \& Bayen, 2006). Both studies were conducted in accordance with the university's ethics guidelines; participants provided informed consent, were debriefed, and financially compensated for their participation.

\section{Results and Discussion}

Importance-Incentive Relation. We first analyzed the relation between perceived importance and motivational-incentive condition. The two variables were uncorrelated, $r=$ 
$.03, \mathrm{BF}_{10}=0.22{ }^{1}$

Memory Performance. We used Bayesian regression ${ }^{2}$ to quantify evidence for the absence/presence of a relation between age and memory performance and to analyze whether this relation was moderated by our motivational manipulation and perceived task importance. For this purpose, we entered $z$-standardized scores of age, importance, and incentive/framing condition (effect coded: gains $=-1$; losses $=+1$ ) and compared a series of regression models that differed systematically in terms of the included main effects and interactions to predict memory performance. The use of BFs makes it possible to compare the predictive adequacy of competing models.

As shown in Table 2, all models received overwhelming evidence in comparison to the Null model, suggesting that the included predictor variables are relevant to account for memory performance. Model $\mathrm{M}_{2}$ (including main effects of Age, Importance, and interactions of Age $\times$ Losses, Age $\times$ Importance) outperformed the Null model the most and also received most support in comparison against all other candidate models $\left(\mathrm{BF}_{\mathrm{M}} \approx 7.80\right)$.

Memory performance is in Table 3. Regarding the regression coefficients, ${ }^{3}$ the data supported inclusion of the variables $\operatorname{Age}\left(\beta=-.13, \mathrm{CI}=[-.26, .00], \mathrm{BF}_{\text {inclusion }}=5.81\right)$ and Importance $\left(\beta=.51, \mathrm{CI}=[.37, .64], \mathrm{BF}_{\text {inclusion }}>100\right)$. That is, memory performance decreased with age and was higher for people who rated the memory task as more important. Inclusions of the interactions Age $\times \operatorname{Importance}\left(\beta=-.15, \mathrm{CI}=[-.27, .00], \mathrm{BF}_{\text {inclusion }}=9.44\right)$ and Age $\times$ Losses $\left(\beta=.14, \mathrm{CI}=[.00, .27], \mathrm{BF}_{\text {inclusion }}=7.53\right)$ also received support from the data, whereas there was little evidence for the inclusion of the main effect of Losses $(\beta=.05$, $\left.\mathrm{CI}=[-.04, .19], \mathrm{BF}_{\text {inclusion }}=1.75\right)$. The Age $\times$ Importance interaction was due to a stronger relation between importance and $\mathrm{PM}$ in younger adults $\left(r=.70, \mathrm{BF}_{10}>100\right)$ than in older adults $\left(r=.34, \mathrm{BF}_{10}>3.50\right)$. Notably, the Age $\times$ Losses interaction was due to more stable memory performance across age in the loss condition than in the gain condition: follow-up 
analyses showed that PM did not decrease with age in the loss condition, $r=-.01, \mathrm{BF}_{10}=$ 0.15; in contrast, $\mathrm{PM}$ decreased with age in the gain condition, $r=-.30, \mathrm{BF}_{10}=3.89$. This may suggest that avoidance of negative consequences following memory failure is particularly relevant for older adults and enhances their memory performance.

\section{Study 2}

In Study 2, we examined gain/loss incentive effects on memory performance across adulthood in a typical experimental PM setting (Einstein \& McDaniel, 1990). Participants were engaged in a lexical-decision ongoing task in which target events could occur. This allowed us to analyze the interplay between PM and ongoing-task performance. Moreover, the experiment had several interrelated aims: First, to compare motivational-incentives effects to a condition in which people are not rewarded contingent on memory accuracy (the typical situation in PM studies), the study included a control group that did not receive performance-contingent payoffs. Given that motivational intensity increases through incentives (Braver et al., 2014), we expected that both gains and losses enhance PM performance. There is also initial evidence from research with younger adults that PM is higher in the presence of both reward and punishment, relative to non-incentivized control conditions (Cook et al., 2015). Second, we allowed participants to freely choose the amount of payoff that they could keep for themselves. Because the relevance of social donations may differ between younger and older adults (Freund \& Blanchard-Fields, 2014), this approach allowed us to match the subjective consequences following memory failure or success through a revealed-preference approach (Samuelson, 1948). Third, we measured the cognitive components contributing to PM with a cognitive mathematical model (multinomial processing tree model of PM; Horn et al., 2011; Smith \& Bayen, 2006). This allowed us to disentangle potential motivational effects on the prospective component (becoming aware at the right moment that one had an intention) and retrospective component (recognition of 
target events) of the PM task. Finally, we examined whether incentives induce more or less effortful maintenance of intentions. In general, motivational incentives may influence PM at different phases throughout a task (i.e., at formation, retention, initiation, or execution of an intention; Penningroth \& Scott, 2007). As one possible scenario, motivational incentives could induce attentional monitoring to detect PM targets, which would come at a cost of greater interference with ongoing tasks (e.g., Smith et al., 2007). In this case, we would expect lower ongoing-task performance in the incentivized relative to non-incentivized conditions (higher response times and/or lower accuracy). As an alternative scenario, motivational incentives could substantially reduce or eliminate the need for active monitoring (cf. McDaniel \& Einstein, 2000), through different cognitive mechanisms (e.g., enhanced encoding; higher accessibility of intentions during the retention phase; or higher salience of associated target events). Although this study was not designed to disentangle which of these specific mechanisms best explains the data, in this scenario, we would expect no differences in ongoing-task performance between conditions, despite higher PM in the incentivized conditions.

\section{Method}

Participants and design. We aimed at an approximately equal proportion of younger $(<35$ years; $n=94)$, middle-aged $(35-60$ years; $n=76)$, and older adults ( $>60$ years; $n=91)$. The final sample in Study 2 included 261 adults (59\% female) in the age range 18 to 81 years (Table 1), who participated online. Participants were native English speakers, they reported good health, were debriefed, and received 2.5USD for participation. Participants were randomly assigned to one of three experimental conditions (gains; losses; control); participants' chronological age and their perceived task importance were included as continuous variables in the analyses.

Materials. We used word stimuli from the English-lexicon-project database (Balota et 
al., 2007) with Kučera-Francis frequency of 4-5 per million, word length 6-8 letters, and 2-3 syllables. To make the ongoing task challenging, we selected words for which classification accuracy was lower than $90 \%$ from the database. From this larger set, we selected 10 targets and 224 filler words that did or did not include the syllable ing, respectively. Half of the targets and filler words, respectively, were randomly selected and transformed into nonwords by changing one vowel within a letter string. The nonwords were screened by a native speaker to ensure that the strings were not coincidentally transformed into another English word.

Procedure. After completion of a demographic questionnaire, participants practiced 24 trials of a lexical-decision task in which black lowercase letter strings (sans-serif font) were presented sequentially in the middle of a white screen (50\% words; $50 \%$ nonwords). Participants were asked to make word/nonword decisions quickly and accurately. During practice, they received feedback for correct and error responses and the program started the next trial if no response was given within 4 s following stimulus onset. Participants then received instructions for an event-based PM task: they were asked to remember to press the spacebar key (instead of providing a word/nonword response) whenever a letter string included the syllable ing. Participants were shown two targets as examples (walking; ingbar) that did not occur in the subsequent phase. In the control condition, participants received no further instructions. In the gain-frame condition, participants were informed that they could accumulate additional 2.5USD, contingent on the proportion of PM targets they would respond to correctly ( +25 cent/target). In the loss-frame condition, participants were informed that they additionally received an initial endowment of 2.5USD from which money could be subtracted, contingent on the proportion of PM targets they would miss ( -25 cent/target). Participants from both motivational-incentive conditions were then informed that they could freely choose how much from the additional performance-based payoff would later go to 
themselves or a donation and entered a number from 0 to $100 \%$ indicating their choice.

After a brief delay, participants completed 210 trials of a lexical-decision ongoing task (50\% words) with an embedded event-based PM task ( 5 word and 5 nonwords targets). Target events occurred on trials $21,42,63,84,105,126,147,168,189,210$. PM accuracy was measured as the proportion of targets correctly responded to. We included the same checks as in the previous study to ensure that participants understood the PM instructions (people who could not indicate the PM key and additionally never pressed the PM key during the study were excluded from further analyses; $n=8$ out of 269 participants in Study 2). Finally, participants entered a number, between 0 (unimportant) to 100 (very important), indicating PM task importance.

\section{Results and Discussion}

Importance-Incentive Relation. There was no relation between perceived importance and motivational incentive/framing condition, $r=.05, \mathrm{BF}_{10}=0.21$.

Memory performance. As in the previous study, we examined if and how the relation between age and memory performance (Table 3 ) was moderated by our motivational incentive/framing manipulation and task importance. For this goal, $z$-standardized scores of age, importance, and framing (effect coded: gains $=-1$; control $=0$; losses $=+1$ ) were entered in a series of regression models that differed systematically regarding the included main effects and interactions (Table 2).

All considered models outperformed the Null model, suggesting that the included predictor variables were relevant to account for variability in memory performance. Model $\mathrm{M}_{2}$ (including an effect of Losses, Importance, and interactions of Age $\times$ Losses, Age $\times$ Importance on memory performance) outperformed the Null model the most and received most support in comparison against all other candidate models $\left(\mathrm{BF}_{\mathrm{M}} \approx 27.35\right)$.

Regarding the regression coefficients in the model, the data supported inclusion of the 
predictor Importance $\left(\beta=.15, \mathrm{CI}=[.00, .25], \mathrm{BF}_{\text {inclusion }}=13.16\right)$, of a Losses effect $(\beta=.16$, $\left.\mathrm{CI}=[.00, .33], \mathrm{BF}_{\text {inclusion }}=6.59\right)$, and of an Age $\times$ Losses interaction $(\beta=.15, \mathrm{CI}=[.00, .31]$, $\left.\mathrm{BF}_{\text {inclusion }}=5.23\right)$. There was also some evidence for an Age $\times$ Importance interaction $(\beta=.09$, $\left.\mathrm{CI}=[.00, .23], \mathrm{BF}_{\text {inclusion }}=3.47\right)$. However, the data did not support inclusion of an effect of Gains $\left(\beta=.05, \mathrm{CI}=[-.04, .22], \mathrm{BF}_{\text {inclusion }}=1.28\right)$, of Age, or of the Age $\times$ Gains interaction in the model $(0.81<\mathrm{BFs}<1)$. Thus, memory performance was expectedly higher for people who perceived the memory task as more important and there was indication that losses (following memory failure) increased performance. The enhancing effects of losses and importance on PM were more pronounced in older than younger adults (as indicated by the positive Age $\times$ Losses and Age $\times$ Importance coefficients, respectively).

Ongoing-Task Performance. We calculated each participant's mean accuracy and median response time on nontarget trials in the ongoing lexical-decision task (Table 3). We then included the same predictors as in our analyses of PM to analyze ongoing-task performance in series of Bayes-regression models. There was only strong evidence for an effect of age on accuracy $\left(\beta=.32, \mathrm{CI}=[.21, .42], \mathrm{BF}_{\text {inclusion }}>100\right)$ and on response time $(\beta=$ $\left..22, \mathrm{CI}=[.10, .36], \mathrm{BF}_{\text {inclusion }}=32.00\right)$, respectively, with older participants responding more slowly and accurately than younger participants. This replicates a common pattern between age groups in the lexical-decision task (Ball \& Aschenbrenner, 2018; Horn et al., 2013). Notably, there was no evidence for further main effects or for interactions with the motivational-incentive conditions $(0.10<$ all BFs $<1)$, suggesting that differences in memory performance between conditions are unlikely due to trade-offs with ongoing-task performance.

Cognitive Modeling. To gain further insight into the cognitive components underlying PM, we fit a multinomial model ${ }^{4}$ to the data (Horn et al., 2011). This model has three free parameters that are estimated from people's responses in an event-based PM task: parameter 
$P$, measuring the probability of becoming aware at the relevant moment that one had an intention (prospective component); parameter $M$, measuring the probability of accurately recognizing a target (retrospective component); parameter $C$, measuring the probability of correctly responding to an ongoing-task stimulus. We regressed all model parameters on the same predictors as in the previous analyses, using a Bayesian multi-level approach (Klauer, 2010). Regarding model parameter $P$, we found effects of Importance $\left(\mathrm{BF}_{10}=7.38\right)$ and an Age $\times$ Importance interaction $\left(\mathrm{BF}_{10}=3.66\right)$. This dovetails with previous research, in which emphasizing the importance of a PM task increased the prospective-component parameter (Smith \& Bayen, 2004); moreover, it has been suggested that importance instructions may be more beneficial for older than younger adults' PM if ongoing tasks require little attentional control (e.g., lexical decisions; Ball \& Aschenbrenner, 2018). Regarding model parameter $M$ (retrospective recognition), we found an Age $\times$ Losses interaction $\left(\mathrm{BF}_{10}=6.3\right)$. This suggests that motivational incentives enhance PM through better target recognition, particularly in older adults. Regarding model parameter $C$, we found a main effect of Age $\left(\mathrm{BF}_{10}>100\right)$ suggesting that older adults made more accurate ongoing lexical decisions than younger adults.

Payoff decision. We further analyzed whether the percentage of payoff that participants decided to keep for themselves versus to donate varied with age or differed between the gain or loss conditions (Table 3). Regression analyses did not indicate any effects on this variable $\left(0.1<\mathrm{BFs}_{10}<1\right)$.

\section{General Discussion}

We investigated whether gain or loss consequences have different impact on memory performance in younger, middle-aged, and older adults. Based on propositions from lifespan motivation research, we assumed that avoidance of losses following memory failure could be a stronger motivator for older than younger adults' performance, because losses are often 
costlier to overcome in older age (Baltes et al., 1998; Freund \& Ebner, 2005; Heckhausen et al., 1989). In line with this, the relation between age and memory performance was moderated by motivational valence in two studies (with different materials, procedures, participant pools), indicating a relatively robust pattern: with higher age, people showed relatively better memory performance to avoid losses than to achieve gains. PM decreased across age in the gain and control conditions, whereas performance remained relatively stable in the loss conditions. There was also indication in Study 2 that losses, regardless of age, enhanced PM relative to a non-incentivized control condition. Overall, these findings suggest that losses may have relatively stronger effects on memory performance with increasing age and demonstrate for the first time that motivational incentives may enhance both younger and older adults' PM in laboratory tasks (Aberle et al., 2010; Cook et al., 2015).

Contrary to expectations, younger adults showed similar memory performance in the gain, loss, and control conditions. Based on our theorizing, we had anticipated a stronger advantage for gain over loss related consequences on younger adults' memory (cf. Castel et al., 2016). Interestingly, however, the current findings are consistent with prior PM studies in which college students also did not show performance differences between gain and loss conditions (Cook et al., 2015). This may suggest that younger adults are generally more motivated in computerized lab-based tasks than older adults (Schnitzspahn et al., 2011) _ regardless of the specific incentives that are at stake. It is an avenue for further research to examine the relative impact of gains and losses outside laboratory settings, where younger adults' performance may depend more strongly on motivational incentives (Aberle et al., 2010).

The current studies further indicate that people's perceived task importance is a key predictor of PM performance. Importance and motivational incentives had independent effects on PM and both moderated the relation between age and memory. This suggests that 
the two variables may reflect different motivational components that affect PM, given that they were uncorrelated in both studies. It could be informative to routinely include measures of perceived importance in PM studies as an indicator of people's interest in performing the tasks, which may not necessarily be tied to other motivational manipulations (cf. Walter \& Meier, 2014).

Intended actions that are incentivized or perceived as important may improve PM through different cognitive processes (Penningroth \& Scott, 2007). Given that PM, but not ongoing-task performance, differed between the experimental conditions, the present findings indicate that incentive effects on PM are not necessarily associated with substantial changes in speed or accuracy of ongoing-task responses (see Cook et al., 2015, for similar findings with younger adults). One potential explanation is that incentives facilitate the detection of target events. An attention-capturing target may stimulate activation of an intention, even if that intention has not been actively maintained before (Smith et al., 2007). So far, beneficial effects of salience on PM have mainly been found for semantic and perceptual features: For instance, participants show high PM with only minimal ongoing-task slowing when a PM task involves semantically salient targets (participants' names) or perceptually salient targets (red letter-strings) embedded in a lexical-decision task (Smith et al., 2007). Incentives may have similar effects and induce motivational salience (e.g., Cunningham \& Brosch, 2012), implying that personally relevant information could greatly reduce the need for active monitoring to detect target events. Further research needs to delineate these cognitive mechanisms in more detail; however, the current studies highlight the possibility that motivational incentives have the potential to enhance older adults' PM performance with little extra cost (for a discussion of potentially related effects through the use of motivational implementation-intention strategies, see Gollwitzer \& Cohen, 2008).

Higher age was associated with lower PM in Study $1(\mathrm{BF}=5.81)$, but there was no 
main effect of age in Study $2(\mathrm{BF}=0.80)$. Similar levels of PM performance for younger and older adults may appear surprising, but have been found in several previous studies (e.g., Einstein \& McDaniel, 1990), suggesting that the magnitude of age differences in PM depends on task characteristics (Henry et al., 2004). The use of one single target syllable (ing) and the relatively stable performance across age in the loss condition may have contributed to that pattern. Moreover, the sample in Study 2 included relatively younger older adults (the percentages of participants over 69 years were 18\% vs. $8 \%$ in Studies 1 and 2, respectively).

In conclusion, the present research sheds first light on the interplay between motivational incentives and memory for intentions across adulthood. The findings suggest that the framing of outcomes as gains or losses may not only influence people's judgments and decisions (e.g., McNeil et al., 1982) but may also affect how well younger and older adults remember to do things. Under specific circumstances, older adults' memory performance may benefit when messages encourage the avoidance of losses. An interesting avenue for future research could be to investigate incentive effects in applied naturalistic settings (e.g., regarding health-related behavior). 


\section{References}

Aberle, I., Rendell, P. G., Rose, N. S., McDaniel, M. A., \& Kliegel, M. (2010). The age prospective memory paradox: Young adults may not give their best outside of the lab. Developmental Psychology, 46, 1444-1453. https://doi.org/10.1037/a0020718

Ball, B. H., \& Aschenbrenner, A. J. (2018). The importance of age-related differences in prospective memory: Evidence from diffusion model analyses. Psychonomic Bulletin \& Review, 25, 1114-1122. https://doi.org/10.3758/s13423-017-1318-4

Balota, D. A., Yap, M. J., Hutchison, K. A., Cortese, M. J., Kessler, B., Loftis, B., ... \& Treiman, R. (2007). The English lexicon project. Behavior Research Methods, 39, 445-459. https://doi.org/10.3758/BF03193014

Baltes, P. B., Lindenberger, U., \& Staudinger, U. M. (1998). Life-span theory in developmental psychology. In R. M. Lerner (Ed.), Handbook of child psychology: Vol. 1. Theoretical models of human development (pp. 1029-1143). New York: Wiley. https://doi.org/10.1002/9780470147658.chpsy0111

Bowen, H. J., \& Spaniol, J. (2017). Effects of emotion and motivation on memory dissociate in the context of losses. Learning and Motivation, 58, 77-87. https://doi.org/10.1016/j.lmot.2017.05.003

Brandimonte, M. A., Ferrante, D., Bianco, C., \& Villani, M. G. (2010). Memory for prosocial intentions: When competing motives collide. Cognition, 114, 436-441. https://doi.org/10.1016/j.cognition.2009.10.011

Braver, T. S., Krug, M. K., Chiew, K. S., Kool, W., Westbrook, J. A., Clement, N. J., ... \& Cools, R. (2014). Mechanisms of motivation-cognition interaction: challenges and opportunities. Cognitive, Affective, \& Behavioral Neuroscience, 14, 443-472. https://doi.org/10.3758/s13415-014-0300-0

Castel, A. D., Friedman, M. C., McGillivray, S., Flores, C. C., Murayama, K., Kerr, T., \& 
Drolet, A. (2016). I owe you: Age-related similarities and differences in associative memory for gains and losses. Aging, Neuropsychology, and Cognition, 23, 549-565. https://doi.org/10.1080/13825585.2015.1130214

Cohen, A. L., \& Hicks, J. L. (2017). Prospective memory: Remembering to remember, remembering to forget. Cham, Switzerland: Springer International. https://doi.org/10.1007/978-3-319-68990-6

Cook, G. I., Rummel, J., \& Dummel, S. (2015). Toward an understanding of motivational influences on prospective memory using value-added intentions. Frontiers in Human Neuroscience, 9, 278. https://doi.org/10.3389/fnhum.2015.00278

Craik, F. I. M. (1986). A functional account of age differences in memory. In F. Klix \& H. Hagendorf (Eds.), Human memory and cognitive capabilities (pp. 409-422). Amsterdam: Elsevier.

Cunningham, W. A., \& Brosch, T. (2012). Motivational salience: Amygdala tuning from traits, needs, values, and goals. Current Directions in Psychological Science, 21, 5459. https://doi.org/10.1177/0963721411430832

Depping, M., \& Freund, A. M. (2013). When choice matters: Task-dependent memory effects in older adulthood. Psychology and Aging, 28, 923-936. https://doi.org/10.1037/a0034520

Einstein, G. O., \& McDaniel, M. A. (1990). Normal aging and prospective memory. Journal of Experimental Psychology: Learning, Memory, and Cognition, 16, 717-726. https://doi.org/10.1037/0278-7393.16.4.717

Erdfelder, E., Auer, T. S., Hilbig, B. E., Aßfalg, A., Moshagen, M., \& Nadarevic, L. (2009). Multinomial processing tree models: A review of the literature. Zeitschrift für Psychologie/Journal of Psychology, 217, 108-124. https://doi.org/10.1027/0044$\underline{3409.217 .3 .108}$ 
Freund, A. M., \& Blanchard-Fields, F. (2014). Age-related differences in altruism across adulthood: Making personal financial gain versus contributing to the public good. Developmental Psychology, 50, 1125-1136. https://doi.org/10.1037/a0034491

Freund, A. M., \& Ebner, N. C. (2005). The aging self: Shifting from promoting gains to balancing losses. In W. Greve, K. Rothermund, \& D. Wentura (Eds). The adaptive self: Personal continuity and intentional self-development (pp. 185-202). Ashland, OH: Hogrefe \& Huber Publishers.

Gollwitzer, P. M., \& Cohen, A.-L. (2008). Commentary: Goals and the intentions meant to fulfill them. In M. Kliegel, M. A. McDaniel, \& G. O. Einstein (Eds), Prospective memory: Cognitive, neuroscience, developmental, and applied perspectives (pp. 433439). Mahwah, NJ: Lawrence Erlbaum.

Hargis, M. B., Siegel, A. L. M., \& Castel, A. D. (2019). Motivated memory, learning, and decision-making in older age: Shifts in priorities and goals. In G. R. Samanez-Larkin (Ed.), The aging brain: Functional adaptation across adulthood (pp. 135-163).

Washington, DC: American Psychological Association. https://doi.org/10.1037/0000143-006

Heck, D. W., Arnold, N. R., \& Arnold, D. (2018). TreeBUGS: An R package for hierarchical multinomial-processing-tree modeling. Behavior Research Methods, 50, 264-284. https://doi.org/10.3758/s13428-017-0869-7

Heckhausen, J., Dixon, R. A., \& Baltes, P. B. (1989). Gains and losses in development throughout adulthood as perceived by different adult age groups. Developmental Psychology, 25, 109-121. https://doi.org/10.1037/0012-1649.25.1.109

Henry, J. D., MacLeod, M. S., Phillips, L. H., \& Crawford, J. R. (2004). A meta-analytic review of prospective memory and aging. Psychology and Aging, 19, 27-39. https://doi.org/10.1037/0882-7974.19.1.27 
Hess, T. M., \& Emery, L. (2012). Memory in context: The impact of age-related goals on performance. In M. Naveh-Benjamin \& N. Ohta (Eds.), Memory and Aging: Current Issues and Future Directions (pp. 183-214). New York, NY: Psychology Press.

Horn, S. S., Bayen, U. J., \& Smith, R. E. (2013). Adult age differences in interference from a prospective-memory task: A diffusion model analysis. Psychonomic Bulletin \& Review, 20, 1266-1273. https://doi.org/10.3758/s13423-013-0451-y

Horn, S. S., Bayen, U. J., Smith, R. E., \& Boywitt, C. D. (2011). The multinomial model of prospective memory: Validity of ongoing-task parameters. Experimental Psychology, 58, 247-255. https://doi.org/10.1027/1618-3169/a000091

Klauer, K. C. (2010). Hierarchical multinomial processing tree models: A latent-trait approach. Psychometrika, 75, 70-298. https://doi.org/10.1007/s11336-009-9141-0

Kliegel, M., Jäger, T., \& Phillips, L. H. (2008). Adult age differences in event-based prospective memory: A meta-analysis on the role of focal versus nonfocal cues. Psychology and Aging, 23, 203-208. https://doi.org/10.1037/0882-7974.23.1.203

Kliegel, M., Martin, M., McDaniel, M. A., \& Einstein, G. O. (2001). Varying the importance of a prospective memory task: Differential effects across time-and event-based prospective memory. Memory, 9, 1-11. https://doi.org/10.1080/09658210042000003

Kruglanski, A. W., Shah, J. Y., Fishbach, A., Friedman, R., Chun, W. Y., \& Sleeth-Keppler, D. (2002). A theory of goal systems. In M. P. Zanna (Ed.), Advances in Experimental Social Psychology (Vol. 34, pp. 331-378). New York: Academic Press. https://doi.org/10.1016/S0065-2601(02)80008-9

Logie, R. H., \& Maylor, E. A. (2009). An Internet study of prospective memory across adulthood. Psychology and Aging, 24, 767-774. https://doi.org/10.1037/a0015479

Mather, M., \& Carstensen, L. L. (2005). Aging and motivated cognition: The positivity effect in attention and memory. Trends in Cognitive Sciences, 9, 496-502. 
https://doi.org/10.1016/j.tics.2005.08.005

McDaniel, M. A., \& Einstein, G. O. (2000). Strategic and automatic processes in prospective memory retrieval: A multiprocess framework. Applied Cognitive Psychology, 14, S127-S144. https://doi.org/10.1002/acp.775

McNeil, B. J., Pauker, S. G., Sox, H. C., \& Tversky, A. (1982). On the elicitation of preferences for alternative therapies. New England Journal of Medicine, 306, 12591262. https://doi.org/10.1056/NEJM198205273062103

Ogilvie, D. M., Rose, K. M., \& Heppen, J. B. (2001). A comparison of personal project motives in three age groups. Basic \& Applied Social Psychology, 23, 207-215. https://doi.org/10.1207/S15324834BASP2303_ 7

Park, D. C., Hertzog, C., Kidder, D. P., Morrell, R. W., \& Mayhorn, C. B. (1997). Effect of age on event-based and time-based prospective memory. Psychology and Aging, 12, 314-327. https://doi.org/10.1037/0882-7974.12.2.314

Penningroth, S. L., \& Scott, W. D. (2007). A motivational-cognitive model of prospective memory: The influence of goal relevance. In L. V. Brown (Ed.) Psychology of Motivation (pp. 115-128). Hauppauge, NY: Nova Science.

Penningroth, S. L., \& Scott, W. D. (2019). Age-related differences in the goals and concerns that motivate real-life prospective memory tasks. PLOS ONE, 14(6). https://doi.org/10.1371/journal.pone.0216888

Peter, J., \& Kliegel, M. (2018). The age-prospective memory paradox: Is it about motivation? Clinical and Translational Neuroscience, 2(2). https://doi.org/10.1177/2514183X18807103

Phillips, L. H., Henry, J. D., \& Martin, M. (2008). Adult aging and prospective memory: The importance of ecological validity. In M. Kliegel, M. A. McDaniel, \& G. O. Einstein (Eds.), Prospective Memory: Cognitive, Neuroscience, Developmental, and Applied 
Perspectives. Mahwah, NJ: Erlbaum.

Rummel, J., \& McDaniel, M. A. (Eds.). (2019). Prospective Memory. Abingdon, England: Routledge. https://doi.org/10.4324/9781351000154

Samuelson, P. A. (1948). Consumption theory in terms of revealed preference. Economica, 15, 243-253. https://doi.org/10.2307/2549561

Schnitzspahn, K. M., Ihle, A., Henry, J. D., Rendell, P. G., \& Kliegel, M. (2011). The ageprospective memory-paradox: An exploration of possible mechanisms. International Psychogeriatrics, 23, 583-592. https://doi.org/10.1017/S1041610210001651

Scullin, M. K., Bugg, J. M., \& McDaniel, M. A. (2012). Whoops, I did it again: Commission errors in prospective memory. Psychology and Aging, 27, 46-54. https://doi.org/10.1037/a0026112

Smith, R. E., \& Bayen, U. J. (2006). The source of adult age differences in event-based prospective memory: A multinomial modeling approach. Journal of Experimental Psychology: Learning, Memory, and Cognition, 32, 623-635. https://doi.org/10.1037/0278-7393.32.3.623

Smith, R. E., Hunt, R. R., McVay, J. C., \& McConnell, M. D. (2007). The cost of event-based prospective memory: Salient target events. Journal of Experimental Psychology: Learning, Memory, and Cognition, 33, 734-746. https://doi.org/10.1037/02787393.33.4.734

Staudinger, U. M., Marsiske, M., \& Baltes, P. B. (1995). Resilience and reserve capacity in later adulthood: Potentials and limits of development across the life-span. In D. Cicchetti \& D. Cohen (Eds.), Developmental psychopathology: Vol. 2. Risk, disorder, and adaptation (pp. 801 - 847). New York: Wiley. https://doi.org/10.1017/S0954579400006155 
Uttl, B. (2008). Transparent meta-analysis of prospective memory and aging. PloS one, 3, e1568. https://doi.org/10.1371/journal.pone.0001568

Wagenmakers, E. J., Love, J., Marsman, M., Jamil, T., Ly, A., Verhagen, J., ... \& Meerhoff, F. (2018). Bayesian inference for psychology. Part II: Example applications with JASP. Psychonomic Bulletin \& Review, 25, 58-76. https://doi.org/10.3758/s13423-017$\underline{1323-7}$

Walter, S., \& Meier, B. (2014). How important is importance for prospective memory? A review. Frontiers in Psychology, 5, 657. https://doi.org/10.3389/fpsyg.2014.00657 


\section{Footnotes}

${ }^{1}$ A Bayes factor (BF) compares the likelihood of the data under one model $\mathrm{M}_{1}$ (e.g., a model assuming a relation between two variables) to that under another model $\mathrm{M}_{0}$ (e.g., a model assuming no such relation). BF thus quantifies the evidence for one model over another model (i.e., the amount by which the observed data changed one's relative belief about these models) as a ratio of likelihoods on a continuous scale. For example, when $\mathrm{BF}_{10}$ $=7$, the data are seven times more likely under $\mathrm{M}_{1}$ than under $\mathrm{M}_{0}$; when $\mathrm{BF}_{10}=0.1$, the data are ten times more likely under $\mathrm{M}_{0}$ than under $\mathrm{M}_{1}$. $\mathrm{BFs} \mathrm{s}_{10}$ larger than 10 or 100 are usually interpreted to indicate "strong" or "extreme" evidence for $\mathrm{M}_{1}$, respectively; BFs 10 smaller than 0.1 or .001 , respectively, would indicate "strong" or "extreme" evidence for the null model $\mathrm{M}_{0}$; BFs between 1/3 and 3 are interpreted to indicate only equivocal evidence (cf. Wagenmakers et al., 2018).

${ }^{2}$ Our prior distributional assumptions relied on the default settings from the BayesFactor package as implemented in the software JASP that we used for analysis (Wagenmakers et al., 2018). That is, for estimation of regression coefficients, we relied on the common Jeffreys-Zellner-Siow scheme that assigns a multivariate Cauchy distribution to the regression coefficients. The Cauchy is equivalent to a $t$-distribution with $d f=1$ and thus a “fat-tail" symmetric distribution. To complement our Bayesian analyses, we also examined regression coefficients using a frequentist inferential approach (see Supplement 4) which, in the present case, led to conclusions that were not qualitatively different from the Bayesian regression analysis.

${ }^{3}$ The analysis of regression coefficients relied on Bayesian model averaging (Wagenmakers et al., 2018). The goal is to deal with model-selection uncertainty by averaging the conclusions from each candidate model, weighted by the posterior plausibility of that model. $\mathrm{BF}_{\text {inclusion }}$ quantifies the strength of evidence for the inclusion of a predictor, 
averaged across the models under consideration.

${ }^{4}$ Technical details about the modeling are in Appendix B and in Supplement 1.

Further information about the modeling results is in Supplements 2 and 3. 
Table 1 Sample Characteristics in Study 1 and 2

\begin{tabular}{|c|c|c|c|}
\hline & Younger & Middle-Aged & Older \\
\hline & Adults & Adults & Adults \\
\hline \multicolumn{4}{|l|}{ Study 1} \\
\hline \multicolumn{4}{|l|}{ Gender } \\
\hline male & 23 & 22 & 29 \\
\hline female & 25 & 24 & 23 \\
\hline \multicolumn{4}{|l|}{ Education level } \\
\hline $\begin{array}{l}\text { obligatory school or } \\
\text { apprenticeship }\end{array}$ & 13 & 21 & 22 \\
\hline vocational training & 3 & 4 & 9 \\
\hline high school/college & 18 & 11 & 9 \\
\hline university degree & 13 & 10 & 12 \\
\hline \multicolumn{4}{|l|}{ Income } \\
\hline$<39$ & 12 & 4 & 11 \\
\hline $40-99$ & 18 & 24 & 34 \\
\hline$>99$ & 7 & 12 & 10 \\
\hline
\end{tabular}


Table 1 continued

Study 2

Gender

$\begin{array}{llll}\text { male } & 50 & 27 & 28 \\ \text { female } & 42 & 49 & 63\end{array}$

Education level

$\begin{array}{lccc}\text { vocational training } & 3 & 6 & 8 \\ \text { high school (or lower) } & 24 & 15 & 21 \\ \text { college } & 27 & 18 & 13 \\ \text { university degree } & 40 & 37 & 49\end{array}$

Income

$\begin{array}{lccc}<20 & 16 & 19 & 26 \\ 20-40 & 24 & 21 & 29 \\ 40-60 & 19 & 13 & 17 \\ 60-100 & 20 & 11 & 9 \\ >100 & 8 & 8 & 4\end{array}$

Note. Frequency of participants $(n)$ as a function of sample characteristics. Income $=$ yearly income $\times 1000$ in CHF (study 1$)$ or USD (study 2 ); not all participants provided responses on all variables. 
RUNNING HEAD: AGING, MEMORY, GAINS AND LOSSES

Table 2 Comparison of Regression Models Predicting Memory Performance in Study 1 and 2

\begin{tabular}{|c|c|c|c|c|c|c|}
\hline Model & Study 1: Predictors & $P(\mathrm{M})$ & $P($ M $\mid$ data $)$ & $\mathrm{BF}_{\mathrm{M}}$ & $\mathrm{BF}_{10}$ & $R^{2}$ \\
\hline $\mathrm{M}_{0}$ & Null model & 0.167 & $2.562 \mathrm{e}-10$ & $1.281 \mathrm{e}-9$ & 1.000 & 0.000 \\
\hline $\mathrm{M}_{1}$ & Age + Losses + Importance + Age $\times$ Losses + Age $\times$ Importance & 0.167 & 0.529 & 5.614 & $2.065 \mathrm{e}+9$ & 0.355 \\
\hline $\mathbf{M}_{2}$ & Age + Importance + Age $\times$ Losses + Age $\times$ Importance & $\mathbf{0 . 0 3 3}$ & 0.212 & 7.803 & $4.138 \mathrm{e}+9$ & $\mathbf{0 . 3 4 7}$ \\
\hline $\mathrm{M}_{3}$ & Importance + Age $\times$ Losses + Age $\times$ Importance & 0.017 & 0.043 & 2.647 & $1.676 \mathrm{e}+9$ & 0.322 \\
\hline $\mathrm{M}_{4}$ & Losses + Importance + Age $\times$ Losses + Age $\times$ Importance & 0.033 & 0.039 & 1.172 & $7.584 \mathrm{e}+8$ & 0.330 \\
\hline $\mathrm{M}_{5}$ & Age + Importance + Age $\times$ Importance & 0.017 & 0.030 & 1.839 & $1.180 \mathrm{e}+9$ & 0.319 \\
\hline $\mathrm{M}_{6}$ & Age + Losses + Importance + Age $\times$ Importance & 0.033 & 0.028 & 0.822 & $5.383 \mathrm{e}+8$ & 0.327 \\
\hline $\mathrm{M}_{7}$ & Age + Losses + Importance + Age $\times$ Losses & 0.033 & 0.020 & 0.601 & $3.963 \mathrm{e}+8$ & 0.324 \\
\hline $\mathrm{M}_{8}$ & Age + Importance + Age $\times$ Losses & 0.017 & 0.020 & 1.217 & $7.888 \mathrm{e}+8$ & 0.315 \\
\hline $\mathrm{M}_{9}$ & Importance & 0.033 & 0.018 & 0.545 & $3.600 \mathrm{e}+8$ & 0.269 \\
\hline $\mathrm{M}_{10}$ & Importance + Age $\times$ Importance & 0.017 & 0.017 & 1.017 & $6.613 \mathrm{e}+8$ & 0.295 \\
\hline $\mathrm{M}_{11}$ & Importance + Age $\times$ Losses & 0.017 & 0.014 & 0.814 & $5.316 \mathrm{e}+8$ & 0.293 \\
\hline $\mathrm{M}_{12}$ & Age + Importance & 0.017 & 0.010 & 0.579 & $3.791 \mathrm{e}+8$ & 0.289 \\
\hline
\end{tabular}


Table 2 continued

\begin{tabular}{|c|c|c|c|c|c|c|}
\hline Model & Study 2: Predictors & $P(\mathrm{M})$ & $P(\mathrm{M} \mid$ data $)$ & $\mathrm{BF}_{\mathrm{M}}$ & $\mathrm{BF}_{10}$ & $R^{2}$ \\
\hline $\mathrm{M}_{0}$ & Null model & 0.125 & 0.005 & 0.038 & 1.000 & 0.000 \\
\hline $\mathrm{M}_{1}$ & Age + Gains + Losses + Importance + Age $\times$ Gains + Age $\times$ Losses + Age $\times$ Importance & 0.125 & 0.165 & 1.386 & 31.008 & 0.108 \\
\hline $\mathbf{M}_{2}$ & Losses + Importance + Age $\times$ Losses + Age $\times$ Importance & 0.004 & 0.089 & 27.354 & 586.438 & 0.101 \\
\hline $\mathrm{M}_{3}$ & Gains + Losses + Importance + Age $\times$ Gains + Age $\times$ Losses + Age $\times$ Importance & 0.018 & 0.067 & 3.940 & 87.809 & 0.107 \\
\hline $\mathrm{M}_{4}$ & Age + Gains + Losses + Importance + Age $\times$ Losses + Age $\times$ Importance & 0.018 & 0.065 & 3.840 & 85.720 & 0.106 \\
\hline $\mathrm{M}_{5}$ & Gains + Losses + Importance + Age $\times$ Losses + Age $\times$ Importance & 0.006 & 0.064 & 11.508 & 254.047 & 0.105 \\
\hline $\mathrm{M}_{6}$ & Losses + Importance + Age $\times$ Gains + Age $\times$ Losses + Age $\times$ Importance & 0.006 & 0.047 & 8.317 & 186.946 & 0.103 \\
\hline $\mathrm{M}_{7}$ & Age + Losses + Importance + Age $\times$ Gains + Age $\times$ Losses + Age $\times$ Importance & 0.018 & 0.046 & 2.664 & 60.690 & 0.104 \\
\hline $\mathrm{M}_{8}$ & Age + Losses + Importance + Age $\times$ Losses + Age $\times$ Importance & 0.006 & 0.045 & 7.936 & 178.775 & 0.102 \\
\hline $\mathrm{M}_{9}$ & Losses + Importance + Age $\times$ Losses & 0.004 & 0.042 & 12.158 & 274.247 & 0.085 \\
\hline $\mathrm{M}_{10}$ & Losses + Importance + Age $\times$ Importance & 0.004 & 0.020 & 5.607 & 129.384 & 0.079 \\
\hline $\mathrm{M}_{11}$ & Gains + Importance + Age $\times$ Losses + Age $\times$ Importance & 0.004 & 0.018 & 5.171 & 119.523 & 0.089 \\
\hline $\mathrm{M}_{12}$ & Losses + Importance & 0.006 & 0.018 & 3.019 & 69.977 & 0.062 \\
\hline
\end{tabular}


Note. In all models, PM accuracy is the criterion. Experimental incentive/framing condition was entered as effect-coded categorical predictor in Study 1 (gains $=-1$; losses $=+1$ ) and Study 2 (gains $=-1$; control $=0$; losses $=+1)$. The null model includes only the grand mean (intercept). In each study, the model that outperformed the Null model the most and received most support by the data in comparison against the other candidate models is marked in boldface. The selection of the best regression model via BF represents a compromise between explained variance and the principle of parsimony (number of predictors). The column "Predictors" lists the variables included in a specific model to account for memory performance. $P(\mathrm{M})=$ prior model probability initially assigned to a model; $P(\mathrm{M} \mid$ data $)=$ posterior probability of a model after having seen the data; $\mathrm{BF}_{\mathrm{M}}=$ degree to which the data have changed from prior to posterior model odds (comparison of each model to the averaged posterior probability of the other models); $R^{2}=$ proportion of criterion variance accounted for by the predictors. The column $\mathrm{BF}_{10}$ shows the Bayes factor for each model against the null model. For example, in Study2, model $\mathrm{M}_{2}$ accounts for the observed data ca. 586 times as well as the null model $\mathrm{M}_{0}$. A comparison between models $\mathrm{M}_{2}$ and $\mathrm{M}_{1}$ yields 586.44 / $31.01 \approx 18.91$, suggesting the data are about 19 times more likely under $\mathrm{M}_{2}$ (which includes four predictors) than $\mathrm{M}_{1}$ (the most complex model including all predictors). We exhaustively considered all regression-model variants on memory performance with different combinations of the predictors age, framing, importance, and their interactions. In the table, only the twelve models $\left(\mathrm{M}_{1}\right.$ to $\left.\mathrm{M}_{12}\right)$ with the highest posterior probability and the Null model are shown. A comprehensive table with all model variants is in the online supplement. 
RUNNING HEAD: AGING, MEMORY, GAINS AND LOSSES

Table 3 Performance in Study 1 and 2:

Prospective Memory, Ongoing-Task, and Importance Ratings

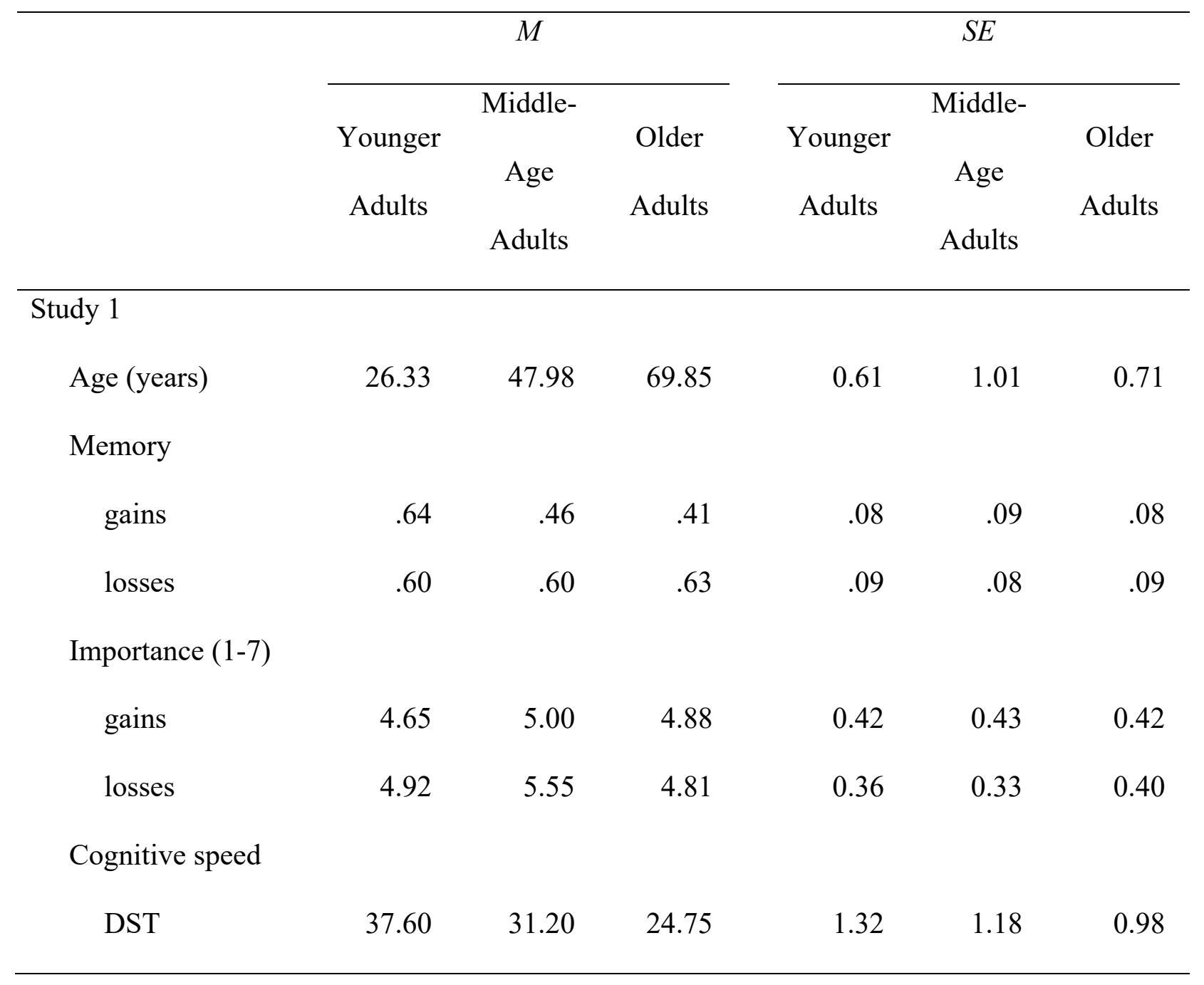


Table 3 continued

Study 2

Age (years)

24.74

44.50

66.15

0.50

0.88

0.45

Memory

gains

.49

.36

.06

.04

.04

losses

.41

.50

.49

.05

.05

.06

control

.43

.31

.31

.05

.04

.04

Accuracy

gains

.90

.92

.92

.01

.01

.01

losses

.89

.91

.94

.01

.01

.01

control

.89

.92

.94

.01

.01

.01

RT (ms)

gains

964

994

1091

28

73

56

losses

915

1001

1020

53

49

35

control

954

990

1105

44

58

47

$\%$ payoff retained

$\begin{array}{lrrrrrr}\text { gains } & 83.47 & 87.39 & 74.26 & 5.07 & 5.42 & 5.83 \\ \text { losses } & 87.10 & 83.42 & 87.63 & 4.77 & 5.34 & 5.33\end{array}$

Importance (0-100)

$\begin{array}{lllllll}\text { gains } & 68.47 & 76.04 & 64.09 & 6.11 & 7.58 & 5.83 \\ \text { losses } & 77.65 & 77.15 & 74.74 & 4.52 & 6.79 & 7.60 \\ \text { control } & 75.04 & 80.65 & 75.51 & 5.05 & 5.75 & 5.81\end{array}$

Note. Memory $=$ proportion of accurate responses on prospective-memory target events; DST $=$ scores in digit-symbol substitution test; Accuracy $=$ proportion of correct word and nonword responses in the ongoing lexical-decision task; RT = median response time in the ongoing 
lexical-decision task (in ms); Importance $=$ self-report ratings of absolute importance of the memory task. 